\title{
The Deficiencies and Improvement in The System of China's Modern Agricultural Industry
}

\section{In Contrast With Modern Agricultural Industrial Systems of Developed Countries}

\author{
Le Xu \\ College of Economy, Tianjin Polytechnic University \\ Postgraduate Student of Industry Economics \\ NO.399 Binshuixi Road, Xiqing District, Tianjin 300387, China \\ E-mail: fredlovejuzi@yahoo.com.cn \\ Ruiqi Qin \\ College of Economy, Tianjin Polytechnic University, China
}

\begin{abstract}
China's agricultural system deficiencies lead to contradictions in agriculture system, it is necessary and reasonable to resolve institutional arrangements and policy options. In this paper, through the analysis of the modern agricultural industrial systems in developed countries, writers put forward China's system of agricultural land, agricultural protection system and the lack of agricultural technology systems and propose countermeasures.
\end{abstract}

Keywords: Modern Agricultural Industry, Deficiencies, Improvement

\section{The Current Situation of Modern Agricultural Industrial System in Major Developed Countries}

\subsection{Agriculture land system in developed countries}

\subsubsection{Clear property rights in agriculture are the Common feature of developed countries and regions}

From the form of ownership, agriculture in developed countries and regions are not identical. Some of them were private property, such as the United States, Japan, Britain and so on; Some of them were state-owned system, such as Australia, Canada, etc. However, no matter what kind of form, its property rights are very clear.

\subsubsection{Give the production operators the right to use the full}

Producers manage their own business is the promotion of agricultural development. The right to make their own decisions is an important sign of the right to use agricultural land. Countries, where agricultural development is faster, have attached great importance to agricultural producers' right to make their own decisions.

1.1.3 The implementation of a series of laws and policies to promote the expansion of the scale of agricultural operations

The United States allows the farm to register as a company or partnership, etc. to expand the scale of land management and eliminate the fragment of agricultural land. The law provides the family members' right to own or inherit farm land and shares, but can not withdrawal the shares or use shares as mortgage, only allow internal transfer, in order to ensure the intergenerational transmission; Britain gives encouragement policy for the expansion of farm size; French encourages middle-farms and provides the transfer of land are inseparable but can only be inherited or transferred as a whole and can only be inherited by one child, etc.

\subsubsection{Develop the social service system vigorously}

To promote the concentration of agricultural land and business of property rights changes in the process, some agricultural countries and region establish a variety of organizations, such as the United States Farm Management Services Company, France's agricultural land groups, in particular, Japan's "hold onto the rationalization of agricultural legal person" has played a very important role in realizing of agricultural land rent-seeking activity. 


\subsection{The system of agricultural science and technology in developed countries}

The development of agriculture in developed countries largely due to their historical experience and trends of strong agricultural science and technology. These states sponsor agricultural education, research and promotion, to enhance the competitiveness of agriculture. In order to reduce and even eliminate differences between workers and peasants, between urban and rural areas, to ensure sustained and stable development of agriculture, the Western countries give great support on agricultural education, research and extension, which is a fundamentally key measure to protect agriculture. American agriculture and education promote the Trinity system. This is its key to realize agricultural modernization. From since the mid-1950s, the American agricultural research funding is for an average annual growth rate of $8 \%$. To promote science and technology in the rural areas, the United States is basically free of charge. Farmers may at any time to research institutions and university research organizations to get guidance and help on science and technology. In recent years, the United State's investment on higher education in agriculture is reaching 100 billion U.S. dollars. Budget for agricultural research is over more than 40 billion U.S. dollars annually, the agricultural research officer has more than 70,000 U.S. dollars in research funding on average.

\subsubsection{Attach importance to the development of agricultural high-tech}

Since 1980s', the U.S. government had taken the development of the high-tech applications in agriculture as a potential force for agricultural development policies in science and technology development, and taken agricultural biotechnology, agriculture information technology as two major high-tech technologies in 21 century. Currently, the U.S. supports biotechnology industry at the policy level. First, setting up a special organization and leadership of institutions; the second is to develop a series of conservation and to encourage the development of biotechnology policy and law; the third is to build a variety of financing channels to achieve the support to the biotechnology industry.

1.2.2 Attach importance to environmental protection, taking the way of sustainable agricultural development

In the United States, for those who are unable to obtain short-term direct economic benefits, while social and ecological benefits of projects and basic research are significant, the Government will give priority and support, such as agriculture soil environment, crop germ resources, agricultural biotechnology and agricultural basic researches.

\section{China's Deficiencies in Agricultural System, in Contrast with the Developed Countries}

\subsection{Deficiencies in the agricultural land system}

\subsubsection{China's current property rights of land system is incomplete}

These mainly include: first, the hypothetical ownership. Second, the ownership is of disorder. Third, stability is poor. Fourth, the land transfer property is poor.

\subsubsection{The ambiguity and non-exclusive of rural land property rights}

From the perspective of property rights economics, China's agricultural land ownership is not clear, in addition to absence of rural land owners, also because exclusion of farmers' land using rights, income rights and the transfer right are even worse. Ambiguity of rural land property is mainly caused by the non-exclusive property rights. Exclusion of rural land property rights is poor mainly because of the operation of administrative means, rather than the law related.

\subsubsection{The indivisibility and non-transferability of rural land property rights}

Rural land is collection of a variety of properties and a variety of rights, under the existing system, farmers have a right to contract land can manage or abandon land, but can not mortgage or transfer the land. Farmers have no right to lend different properties and different rights to other people. Thus, the contract of the land property rights is indivisibility. It is precisely because of this indivisibility, that land has been tied to an existing contractor, even if other people have better knowledge and skills can not be the land users. Scare rural land can not flow from low-productivity areas to high productivity areas, resulting in the current dilemma in rural areas where lands with no one to farm and people with no land to plant.

\subsection{Deficiencies in China's agricultural science and technology system}

In generally, China's barriers in current slow progress of agricultural science and technology system are mainly in the following areas.

\subsubsection{The institutional obstacles}

History of the world economic development has proved that the market economy is an efficient allocation of economic resources to the institutional arrangements. Competitive pressures in market-based economic system can effectively promote enterprises seeking to develop momentum from the technological progress. China's current agricultural technology system remains essentially formed under the traditional planned economy system. With the gradual deepening of market economy, its shortcomings become more apparent: (1) Market-oriented research activities are not appropriate. (2) Poor access to agricultural scientific research. (3) The administration of the management of scientific 
research institutions. (4) Promotion of agricultural technology is left behind.

\subsubsection{Funding obstacles}

Funds in China's agricultural science and technology innovation is seriously lacking of. Since 1980s', the Chinese government's investment in agricultural research appeared in a downward trend. In 1996 the government investment in agricultural $\mathrm{R} \& \mathrm{D}$ was only $0.20 \%$, far from the average $1 / 10$ in developed countries. In addition, the Chinese Government's investment in agriculture promotion was only $60 \%-70 \%$ of developed countries. In recent years, due to various reasons, funds of technological innovation in China's agricultural enterprises are more inadequate. On the one hand, small-scale agricultural enterprises and low cost-effectiveness result in a shortage of own funds; On the other hand, due to inefficient agricultural enterprises and low social credit, it is also difficult to raise funds from banks.

\subsubsection{Lag of agricultural technology market}

Technology market is an important intermediary link between diffusion and promotion of technology. Overall, the development of China's agricultural technology market is still relatively slow, the market system is not perfect, agricultural technology and trade account for a lower proportion of the total technology transactions. The outcomes of technological innovation in agriculture are products of enterprises and farmers, but these products need to develop, produce, sell or transfer out, in order to achieve genuine economic and social benefits, they must go through market segments.

\section{Suggestions for the Improving the System of China's Modern Agricultural Industry}

\subsection{Suggestions for agricultural land system}

\subsubsection{Diversify ownership of agricultural land}

It can be seen that a single pattern of property rights system generally reduces a low degree of efficiency but high fairness. The key is to rectify this shortcoming is to promote diverse ownership of agricultural land, clarify property boundaries, which is an effective measure to improve the efficiency of property rights, fair can also be guaranteed by efficiency.

\subsubsection{Provide family the property of land contract}

Practice has proved that the household contract responsibility system is comparably adapt to the current land management, and made remarkable achievements, also have been recognized by hundreds of millions of peasants. Take into account both efficiency and fairness, such a system can not be easily changed. The next step of reform should focus on the long-term effectiveness of the right to contract, and further through the definition and maintenance of property rights to stimulate people's enthusiasm for agricultural inputs and to promote its accumulation.

\subsubsection{Logistics of property rights to agricultural land}

Transaction of ownership of agricultural land is the objective requirements of the inherent law of the land, it must be to guide and regulate as soon as possible. To cultivate transfer mechanism of agricultural land using, to speed up separation of agricultural land ownership and right to use, and to promote the appropriate scale of operation of agricultural land.

\subsection{On Agricultural science and technology system}

\subsubsection{Establish agricultural research, education and complicated government agency}

For a long time, China's agricultural research and production practices are not closely linked. In particular, they are out of line with the market, partly due to grouped mode is not conducive to the promotion of agriculture and the use of scientific and technological achievements. The complex of agricultural science and technology innovation system ensures close integration of agricultural research and production, in order to promote the transformation of agricultural research achievements into productive forces.

\subsubsection{Establish a multi-level, comprehensive, divided clearly agricultural research and innovation system}

Comparative studies have shown that developed countries have formed multi-level agricultural science and technology research institutions that collaborated by the government, local authorities, enterprises or farmer organizations. All of them have attached considerable importance to the investment of agricultural science and technology R \& D, and also developed layers of promoting scientific and technological innovation and popularization. China should learn from developed countries, find the actual situation of China's agriculture containing many levels and division of labors in agricultural research and innovation system.

3.2.3 Clarify priority areas of agricultural technology improvement and allocate same proportion of investment to scientific researches

The developed countries have a combination of their actual situation with a variety of agricultural high-tech and develop sustainably. China is a developing country with limited national resources, so we should find areas of priority 
to develop of agricultural science and technology, combined with China's national conditions. In line with the "Do something, not do something" principle, distribute the proportion of agriculture and scientific research scientifically, to create the most efficient scientific and technological products.

3.2.4 Raise the investment on agricultural research and open up a wide range of financing channels for agricultural science and technology

U.S. federal government's investments on agricultural research, education and promotion are in the ratio of relative stability. The Ministry of Agriculture study put $2 \%-4 \%$ of the total budget to researches. The average level of the world is of $1 \%$, while China is only about $0.2 \%$. It is clear that the intensity of China's agricultural research investment is far lower than those in developed countries, and that of the world average investment and also lower than investments on other fields. Making efforts to increase investment in agricultural research in China is necessary conditions for constantly improving.

\section{References}

Kos, etc. ( 1994 ). Property rights and institutional change. Shanghai People's Publishing House.

Lin Yifu. (1994). Economic Theory of Institutional Change: Change and the mandatory nature of induced changes. Property rights and institutional change. Shanghai People's Publishing House.

Liu Mujun and Zhang Jianbin. (2007). The Economic Analysis of the innovation in China's agriculture. Economies of the North, (04).

Luo Yongfu. (2007). Economic analysis of the changes in China's rural land system. Xinjiang University Philosophy and Social Science Edition, (06).

Xu Guihua. (1996). Ownership structure and property system in China Studies. Inner Mongolia University Press. 